
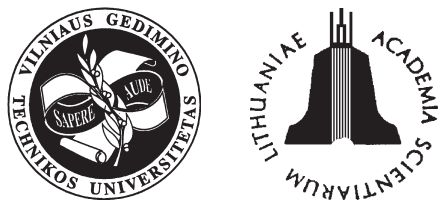

ISSN 1648-4142 TRANSPORT

www.transport.vtu.lt

\title{
EVALUATING EFFICIENCY AND EFFECTIVENESS IN TRANSPORT ORGANIZATIONS
}

\author{
Margarita Išoraitė \\ Mykolas Romeris University of Lithuania, Ateities g. 20, \\ LT-08303Vilnius-57,E-mail:misorait@mruni.lt
}

Received 1 July 2005; accepted 30 September 2005

\begin{abstract}
The article analyses the following issues: 1. Needs of evaluation. 2. Evaluation techniques and tools. 3. Effectiveness, performance and results. 4. Theoretical views on organizational effectiveness. 5. Transport organizational effectiveness. Transport effectiveness refers to the effectiveness of transport agency's organizational systems in achieving its internal and external objectives. 6. Effective internal performance systems. 7. A model of transport organizational effectiveness. 8. Efficiency criterion.
\end{abstract}

Keywords: transport effectiveness, transport efficiency, efficiency criterion.

\section{Introduction}

Economic evaluation usually involves a systematic attempt to identify and, where possible, measure, and compare the costs and outcomes of alternative policies. This is often based on a fairly basic framework, linking the inputs of the programme to outputs and outcomes. One of the principles of economic evaluation is that it should involve a comparison between at least two options: for example a new ,pilot" scheme against an existing programme, or two variants of the same programme. The most „complete” form of economic evaluation is cost-benefit analysis where the costs and benefits of alternative options are valued in monetary terms. Wherever possible, values are put on those goods or services that do not normally have a price attached to them. The option that has the greatest net benefit (or the highest benefit/ cost ratio) is preferred. Cost-benefit analysis has been employed in the evaluation of transport and development projects and, to a lesser extent, in environmental and labour market policies. More common is costeffectiveness analysis where outcomes are measured in physical units, such as numbers of jobs created, reductions in crimes committed, or improvements in a quality of life index. If two or more schemes have similar objectives, then it is possible to compare them in terms of their cost-effectiveness.

"Effectiveness" is a measure of goal achievement. An effective program achieves the goals that have been set in advance for it. The goals themselves may be focused on resources (for example, inputs), pro- cesses and activities (services), results (outcomes), or the social consequences of the results (impacts). Impacts and outcomes are generally considered to be superior to services and input effectiveness criteria, because they focus on what a program or agency actually accomplishes, not merely what it expends or what it does.

"Accountability" is advanced when individuals and transport organizations are held responsible for the operation and effectiveness of programs and institutions under their control. Thus, achieving accountability requires that accurate performance information be collected and reported in some public venue. Accountability systems in the government sector seek to enable clear and accurate "accounting" of what has been accomplished through the use of public funds and the operation of public programs. They also serve as a means of holding public officials and private contractors "accountable" for the lack of accomplishments or the misuse or abuse of public funds and programs.

\section{Needs of evaluation}

Evaluation is an essential component of any expenditure management system. It is the accepted management theory and practices that evaluation findings can assist the government in budgetary decisions and provide the opportunity to improve the management of projects and programs. Without over promising what evaluative activity can deliver, evaluations provide better evidence about what is working and there- 
fore how best to design and deliver policies and programmes to achieve desired outcomes [1]. There are many analytical processes and research that can assist good decision-making. Evaluations rarely give definitive answers. Evaluation makes an important contribution, but not always "the answer". Political considerations are critical. Evaluation provides development managers and civil society with better means for learning from past experience, improving service delivery, planning and allocating resources and demonstrating results as part of accountability. Evaluation ensures that decision makers at all levels have access to the best information available. Evaluation encompasses efficiency (the ability to undertake an activity at the minimum cost possible) and also effectiveness (whether the activity is achieving the objectives which were set for it). The concept of performance should be central. Performance measurement is an essential activity because it provides an opportunity and a framework for asking fundamental questions such as: „What are you trying to achieve?”; „What does “success” look like?”; ,How will you know if or when you've achieved it?" Development of evaluation capacity can support broader governance, institutional development and public sector reform. Successful commercialization and the private sector delivery of budgetary services require a clear understanding of program objectives. The assessments of the performance of alternative service delivery required pre privatization, on an ongoing basis post privatization. Evaluation is a key support to civil service reform. Devolution to managers of increased levels of responsibility and autonomy goes hand in hand with focus on evaluating and appraising the performance of personnel - recognizing that individual performance is reflected to some extent in project or program performance. Evaluation is an important tool to support anti-corruption efforts - improving financial management systems and timely performance reporting. A decision to give priority to evaluation activity will require serious consideration of incentives for decision makers and managers, and of training for managers and evaluators.

\section{Evaluation techniques and tools}

There are many different types of evaluation tools and they can be used in a variety of ways. Although these tools are related, the different terminologies employed by evaluation practitioners can lead to confusion. The tools all address performance measurement are: ongoing monitoring and performance indicators; project and program evaluation - ex ante, ongoing/formative and ex post/summative; performance (or value for-money) audits; financial auditing. Each of these tools provides information on the performance of an activity, and each can be used in a variety of contexts. This broad spectrum of performance measurement activities is also known by other generic labels, such as monitoring and evaluation.

Evaluation describes approaches, techniques and tools for monitoring and evaluation and defines important concepts.

Feedback is defined as a process within the framework of monitoring and evaluation by which information and knowledge are disseminated and used to assess overall progress towards results or confirm the achievement of results. Feedback may consist of findings, conclusions, recommendations and lessons from experience. It can be used to improve performance and as a basis for decision-making and the promotion of learning in an organization.

A "lesson learned" is an instructive example based on the experience that is applicable to a general situation rather than to a specific circumstance. It is learning from experience. Stakeholders are more likely to internalize "lessons learned" if they have been involved in the evaluation process. Lessons learned can reveal "sound practices" that suggest how and why different strategies work in different situations.

The terms „performance measurement” and „evaluation”are often used interchangeably in a generic, shorthand sense to encompass these various terms and concepts. "Evaluation" encompasses a number of related concepts and tools, including [1]:

* Capacities to keep score on effectiveness of budgetary expenditures,

* Specification of project/program objectives and result chains,

* Performance information (including basic data collection),

* Program/project monitoring and evaluation,

* Beneficiary assessment surveys,

* Sector reviews,

* Performance auditing,

* Benchmarking.

There is a variety and range of evaluation techniques, including: cost benefit analysis, economic impact analysis (EIA), modeling, and opinion and client satisfaction surveys.

Performance Indicators. Performance indicators are measures of inputs, processes, outputs, outcomes, and impacts for development projects, programs, or strategies. When supported with sound data collection - perhaps involving formal surveys - analysis and reporting, indicators enable managers to track progress, demonstrate results and take corrective action to improve service delivery.

Benefit - cost and cost - effectiveness analysis. Benefit-cost and cost-effectiveness analysis are tools for 
assessing whether or not the costs of an activity can be justified by the outcomes and impacts. Benefit-cost analysis measures both inputs and outputs in monetary terms. Cost-effectiveness analysis estimates inputs in monetary terms and outcomes in non-monetary quantitative terms. Benefit-cost analysis is a method of evaluating the relative merits of alternative public investment projects. It is the way of identifying, portraying and assessing the factors which need to be considered in making rational economic choices. It entails adjusting conventional business profit and loss calculations of the estimated streams of revenues and costs over the expected life of the project. The streams of revenues and costs occurring over time are compared by discounting them at some selected interest rate to arrive at the present value of benefits and costs. Benefit-cost analysis reflects social instead of private objectives, criteria and constraints in evaluating investment projects. Appraisal of public investment projects entails a wider range of benefits and costs than a private investment. For example, a public transportation project would include environmental costs in addition to transportation costs and savings. The outputs of some public projects do not have market prices associated with them. Benefit-cost analysis imputes dollar values to these outputs, usually by estimating what consumers would be willing to pay for them. Similarly, when inputs of projects do not have market prices, the Litas values of the inputs must be estimated.

The logical framework approach. The logical framework (LogFrame) helps to clarify objectives of any project, program, or policy. It aids in the identification of the expected causal links - the "program logic" - in the following results chain: inputs, processes, outputs (including coverage or "reach" across beneficiary groups), outcomes, and impact. It leads to the identification of performance indicators at each stage in this chain, as well as risks which might impede the attainment of the objectives. The Log Frame is also a vehicle for engaging partners in clarifying objectives and designing activities.

Client satisfaction (or service delivery) survey. A survey is used to assess the performance of government services based on client experience. The survey or questionnaire can shed light on the constraints clients face in accessing public services, their views about the quality and adequacy of services and the responsiveness of government officials. These surveys are usually conducted by a government ministry or agency. Similar to service delivery surveys, they have, for example, investigated the extent of corruption encountered by ordinary citizens. A notable feature has been the widespread publication of the findings.

Rapid appraisal methods survey. Key informant interview - a series of open-ended questions posed to individuals selected for their knowledge and experience in a topic of interest. Interviews are qualitative, in depth, and semi-structured. They rely on interview guides that list topics or questions.

Focus group discussion - a facilitated discussion among 8-12 carefully selected participants with similar backgrounds. Participants might be beneficiaries or program staff, for example. The facilitator uses a discussion guide. Note-takers record comments and observations.

Community group interview - a series of questions and facilitated discussion in a meeting open to all community members. The interviewer follows a carefully prepared questionnaire.

Direct observation - the use of a detailed observation form to record what is seen and heard at a program site. The information may be about ongoing activities, processes, discussions, social interactions, and observable results.

Mini-survey - a structured questionnaire with a limited number of close ended questions that is administered to 50-75 people. The selection of respondents may be random or „purposive”.

Benchmarking. Benchmarking is a technique to exploit the best efficiency and effectiveness result (also called the "best practices zone"). Efficiency is defined as the cost per unit of output. Effectiveness is measured in terms of meeting or exceeding a non-financial performance standard. To establish benchmarks, accurate financial and operational data are required. The best practice is the work processes used to deliver the benchmark result. The work processes are a combination of policies, procedures, and the chain of activities that produce this optimal result. To establish the best practices, the benchmark organization must supply documentation on its policies, procedures, and work processes ("activity maps").

\section{Theoretical views on organizational effectiveness}

Organizational theorists often adhere that the effectiveness of organizations cannot be described in a straightforward manner. Instead, a pluralistic attitude is taken with respect to the interpretation of the concept in question. But it is assumed that interpretation chosen depends on organizational theory and the specific interest of the group posing the question of effectiveness [2]. Therefore the main organizational models used as background for a wide range of definitions of effectiveness will be briefly reviewed.

Economic rationality. The above - mentioned economic definitions of effectiveness are derived from the idea that organizations function rationally - that is to say, with certain goals. Goals that can be opera- 
tional zed as the output to be pursued are the basis for choosing effect criteria (effect criteria being variable used to measure effect). There is evidence of economic rationality whenever the goals are formulated as outputs of the primary production process of the transport organizations. In the functioning of a transport organization as a whole, other, different, goals can also play a part, such as having a clear - cut policy to increase the number of enrolments. Even with regard to this type of objective, transport organization can operate rationally, although it falls outside the specific interpretation given to economic rationality. Effectiveness as defined in terms of economic rationality can also be identified as the productivity of an organization.

The organic system model. According to the organic system model, organization can be compared to biological systems which adapt to their environment. The main characteristic of this approach is that organizations are considered to interact openly with their surroundings. Thus, they need not to be passive objects on environmental manipulation, but they can actively exert influence on the environment. It applies that organizations must be flexible, namely secure essential resources and other inputs. Thus, according to this model flexibility and adoptability are the most important conditions for effectiveness, i.e. for survival.

No matter how strange this view on effectiveness may seem at first glance, it is nevertheless supported in entirely different scientific sphere: microeconomics of the public sector. Nishanen [3] demonstrated that public - sector organizations are primarily targeted at maximizing budgets and that there are insufficient external incentives for the organizations - to encourage effectiveness and efficiency.

Finally, it should also be mentioned that although the organic system model is indeed towards inputs, this does not necessarily exclude a concern for satisfying outputs. This may be the case in situations where the environment makes the availability of inputs dependent on the quantity and/or quality of previous achievement (output).

The human relations approach of organization. If the open - system perception of organizations is an indication towards the environment, in the so-called human relations approach the eye of the organization analyst is focused inward. In Mintzberg's [4] concept of Professional bureaucracy, some aspects of human relations approach are present, namely the emphasis on the well - being of the individuals within an organization, and the importance of consensus and collegial relationships as well as motivation perspective, job satisfaction of workers and their involvement within the organization are appropriate criteria for measuring the most desired characteristics of the organization. The organizational theorists who share this view regard those criteria as effectiveness criteria.
The bureaucracy. The essential problem with regard to the administration and structure of an organization is how to create a harmonious whole. A means for this can be provided through appropriate social interaction and opportunities for personal and Professional development. The second means is provided by organizing clearly defining and formalizing the social relations. The prototype of an organization in which position and duties are formally organized is the bureaucracy. From the perspective, certainty and continuity of the existing organizational structure are the effectiveness criteria. It is well - known that bureaucratic organizations tend to produce more bureaucracy. The underlying motive behind is to ensure the continuation better still, the growth of one's own department. This continuation motive can start operating as an effect criterion in itself.

The political model of organizations. Certain organizational theorists have seen organizations as political batter fields [5]. According to this point of view, departments, individual workers and management staff use official duties and goals in order to achieve their own hidden - or less hidden - agendas. Good contacts with powerful outside bodies are regarded as very important for the standing of their departments. In political perspective the question of the effectiveness of the organization as a whole is difficult to answer. A more relevant question is the extent to which internal groups comply with the demands of certain external interested parties.

Organizational effectiveness model [6]

\begin{tabular}{|l|l|l|l|}
\hline $\begin{array}{l}\text { Theoretical } \\
\text { background }\end{array}$ & $\begin{array}{l}\text { Effectiveness } \\
\text { criterion }\end{array}$ & $\begin{array}{l}\text { Level at } \\
\text { which the } \\
\text { effectiveness } \\
\text { question is } \\
\text { asked }\end{array}$ & $\begin{array}{l}\text { Main areas } \\
\text { of } \\
\text { attention }\end{array}$ \\
\hline $\begin{array}{l}\text { (Business) } \\
\text { economic } \\
\text { rationality }\end{array}$ & Productivity & $\begin{array}{l}\text { The } \\
\text { organization }\end{array}$ & $\begin{array}{l}\text { Outputs } \\
\text { and its } \\
\text { determi- } \\
\text { nants }\end{array}$ \\
\hline $\begin{array}{l}\text { Organic } \\
\text { system theory }\end{array}$ & Adaptability & $\begin{array}{l}\text { The } \\
\text { organization }\end{array}$ & $\begin{array}{l}\text { Acquiring } \\
\text { essential } \\
\text { inputs }\end{array}$ \\
\hline $\begin{array}{l}\text { Human } \\
\text { relations } \\
\text { approach }\end{array}$ & Involvement & $\begin{array}{l}\text { Individual } \\
\text { members of } \\
\text { the } \\
\text { organizations }\end{array}$ & Motivation \\
\hline $\begin{array}{l}\text { Bureaucratic } \\
\text { theory; system } \\
\text { members; } \\
\text { psychological, } \\
\text { homeostatic } \\
\text { theories }\end{array}$ & Continuity & $\begin{array}{l}\text { The } \\
\text { organization } \\
\text { +individuals }\end{array}$ & $\begin{array}{l}\text { Formal } \\
\text { structure }\end{array}$ \\
\hline $\begin{array}{l}\text { Political theory } \\
\text { and how } \\
\text { organization } \\
\text { work }\end{array}$ & $\begin{array}{l}\text { Responsiven- } \\
\text { ess to } \\
\text { external } \\
\text { stakeholders }\end{array}$ & $\begin{array}{l}\text { Sub - groups } \\
\text { and } \\
\text { individuals }\end{array}$ & $\begin{array}{l}\text { Indepen- } \\
\text { dence, } \\
\text { power }\end{array}$ \\
\hline
\end{tabular}


It has already been mentioned that organizational concepts of effectiveness not only depend on theoretical answers to the question of how organizations are ,pieced together”, but also on the position of the functions posing the effectiveness question. At this point there are differences between these five views on organizational effectiveness. With regard to the economic rationality and the organic models, the management of the organization is the main „actor"posing the effectiveness question. As far as the other models are concerned, department heads and individual workers are the actors that seek to achieve certain effects.

In Table the chief characteristics of different theoretical models of organizational effectiveness are summarized.

\section{Effectiveness, performance and results}

Concepts of effectiveness, performance and resultsbased management are commonly used in relation to internal organizational systems. They are similar and are sometimes used interchangeably, and all share a common „results focus”. Performance is usually assessed in terms of results relative to organizational objectives and includes measures of effectiveness. Effectiveness is one aspect of performance, others being economy (cheapest inputs) and efficiency (best output for a given input).

The results focus inherent in concepts of performance and effectiveness assumes a causal chain, which links objectives, inputs and activities to outputs, outcomes and impact.

„Results”refer to the last 3 of these. But there is confusion about the definition of 'outcome'. Sometimes, the term is used to refer to all 3 types of results, at other times to the last two (i.e. intermediate and final outcomes), and yet at other times it refers to intermediate outcomes only [7].

Results Based Management (RBM) is a management tool that helps organizations to focus on results across all their main areas of activity (as opposed to inputs or activities). It assumes:

a) an integrated strategic planning approach, whereby plans are resourced, implemented, monitored and the results fed back into the next planning cycle; each of these elements being oriented towards results;

b) the application of the results focus to all internal business processes (e.g. country programmes, research, policy initiatives) and all levels of the organization (corporate management, divisions, departments, work units, teams, and individuals).

In the private transport sector, results-based management and performance management are in- terchangeable because the results focus is applied mainly to internal organizational objectives (e.g. profitability, productivity, innovation). However, in the aid business the main interest is in „,results”that are external to the organization and take place at a country level. Therefore in aid agencies RBM refers to both the internal performance systems and the orientation of these systems to external country-level results.

\section{Transport organizational effectiveness}

Transport effectiveness refers to the effectiveness of transport agency's organizational systems in achieving its internal and external objectives. The assumption is that effective organizational systems produce consistent standards and behavior in an organization, and ultimately, good country-level results. Poor results can usually be traced in weak organizational systems. For example, projects that are poorly designed suggest inadequate guidance and quality control; uneven staff quality suggests ineffective recruitment and staff development systems; weak country offices suggest insufficient delegated authority; poor partnership behavior suggests week incentives for investing in partnerships, and so on.

It can be focused on eight transport organizational systems: corporate governance; strategic planning, resource management, operational management and delivery, quality assurance, management of staff quality, monitoring, evaluation and lesson learning, and reporting. In relation to these systems, it has identified three aspects or domains of effectiveness: internal performance, the focus on country-level results, and the orientation towards more effective partnerships. Individual aid agencies are likely to be more effective where, for example:

* Their internal performance systems are consistent with their organizational mandate, objectives and comparative advantage; and are oriented towards internal results in all phases of planning, resource allocation, implementation, monitoring and reporting;

* These systems are oriented towards country level results; where relevant, their aid programmes are aligned to national policies and institutions; operational decisions respond flexibly to local demand; there is good knowledge of the local context;

* They promote country ownership and support donor cooperation and harmonization efforts at a country level. The organization is committed to good partnership and seeks feedback on its performance.

\section{Effective internal performance systems}

Most transport agencies have internal performance systems that aim to deliver their internal ob- 
jectives, although these systems may be focused historically on inputs, efficiency etc. Such systems may already be results focused and form a part of an integrated system.

In transport agencies it is possible to identify certain generic internal performance criteria that would apply to any well-functioning organization. It highlights only those aspects that have been deemed to be important in most multilaterals, and are sufficiently generic to be applicable to all [7]:

a) Corporate governance: governing bodies or assemblies should provide strategic guidance on effectiveness issues, encouraging management to act on performance reports, audits and evaluations. An effective governing body gives a consistent strategic direction to the organization and does not give mixed messages, encouraging mission creep etc. It would also encourage mechanisms for managing corporate risk.

b) Corporate strategic planning: An organization's strategic planning mechanisms should reflect its mandate and comparative advantage, linking its objectives at different planning levels. It should have SMART objectives and targets that are based on a clear definition of its mandate and comparative advantage.

c) Resource management: management of resources should be guided by the organization's corporate plans, priorities and targets, which should not be undermined by extra-budgetary funding. It should have an adequate financial control environment, and ensure satisfactory disbursement of resources.

d) Operational management and delivery: The organization should monitor operational management and delivery, simplifying procedures wherever possible. It should track the number of over-age or unsatisfactory projects and have adequate procedures for managing project risk.

e) Quality assurance: Internal quality assurance systems are important to maintain consistently high standards, especially regarding policy advice, project design and implementation. This requires appropriate guidance, internal review, supervision and monitoring at all stages of the project cycle. A well-functioning internal audit system and evaluation office are also important.

f) Management of staff quality: uneven staff quality is a frequent complaint leveled at international organizations. Even where national quotas are in place, recruitment and promotion should be based on meritocratic and transparent principles, and should apply to all jobs including senior management positions. The organizations should collect, monitor and self-report on employment equity and diversity.

g) Monitoring, evaluation and lesson-learning: system should monitor the implementation of the cor- porate strategy throughout the organization, not just project operations. An appropriate flow of statistical information is necessary to be able to track effectiveness results. The system should have effective mechanisms for spreading lesson learning across the organization.

h) Reporting: for accountability and organizational learning, multilaterals should regularly report on progress with the implementation of their corporate commitments and strategies, and these reports should be outcome-focused rather than mere descriptions of activities. The reports should be publicly available.

\section{A model of transport organizational effectiveness}

A model of transport organizational effectiveness reflects the central assumption of theoretical models outlined above: that it is possible and desirable to divide explanatory factors into two main categories: internal and external. External factors arise from the organizational environment, which for public organization means interactions with political institutions and actors. We therefore test the influence of the elected officials, clients, the public and the media, funding constraints, political ideology, political competition, and executive power, on performance.

The internal factors include a range of organizational characteristics that shape management capacity, including the centralization of decision-making authority, organizational culture, the success of leadership in developing results-focus, IT capacity, and worker satisfaction.

\section{Efficiency criterion}

Economic efficiency is widely accepted as the primary objective of transport sector operations and is used, through cost-benefit analysis, to guide project selection and design. However, criteria to guide rational choice become complicated when poverty reduction is a major concern, because the efficiency objective may be in conflict with direct reduction of poverty. A "bias" against the poor may result from the equal weighting given to all income groups in efficiency measures, and their basis in "willingness-topay." This problem arises from the role of income (and wealth) in individual consumer demand and the supply of inputs by resource owners) for transport services and their quality.

Income is a key determinant of individual travel behavior, shaped by the choice of mode and available affordable dwelling location. In general, transport demand is relatively income elastic. Empirical evidence indicates that income elasticity of total travel 
expenditure is typically larger than unity, implying that the share of the budget spent on travel rises from poorer to richer households. Moreover, long-run elasticity of total travel expenditure is invariably above the short-run elasticity, in part because of the ability to exercise wider choices (including mode of transport, vehicle ownership, and relocation) in the long run. On the other hand, however, the very poor often are not able to afford the cost of using "for-payment" transport services. Their main transport mode is walking. They spend a great deal of time and a substantial amount of personal energy on travel, but cover comparatively short distances.

Conventional cost-benefit analysis does not attach specific importance or weights to the social groups that receive project's benefits or incur its costs. An underlying premise of the efficiency criterion of maximum surplus is that a surplus could (that is, has the potential to) be used to compensate all those who lose and still leave the maximum net social gain. In addition, the measures of benefits and costs reflect the prevailing distribution of income (and wealth). Other distributions of income would lead to different valuations of benefits and costs and hence different project choices. It may be argued that this implies reinforcement of the existing distribution of incomeand thereby imposes a "bias" against the poor.

A rigorous cost-benefit analysis requires estimating demand for use of a service by groups of individual users at different price (or generalized user cost) levels. Where possible, revealed preferences are used. Under this procedure, observations of the choice of different price-quantity combinations by the poor reflects highly constrained ability to pay which translates to very low willingness to pay.

Benefits and costs are measured by the aggregation of each individual's willingness to pay, equally weighted (a dollar is a dollar to whom so ever it may accrue). Projects are then selected on the basis of the total willingness to pay less opportunity costs, i.e., the sum of consumers' and producers' surplus. In general (though not always), this favors projects that serve higher-income groups. In an ideal world, the larger total (national) income that results from this could be redistributed at zero or low cost via the tax system. In practice, this is rarely approached and the distributive consequences of the outcome of the cost-benefit analysis may be regarded as less than socially desirable. The issue becomes one of implementing a compensation mechanism or applying a different basis for project choice. For the latter implicit, if not explicit, higher relative weighting of the net benefits to the poor or low-income groups would be required. In short, measures of costs and benefits are dependent on the prevailing income distribution and the contribution of projects at the margin to that distribution; both aspects pose grounds for concern and for possible remedial attention to the poor.

This problem is typical in transport project evaluation where project net benefits to the users are measured by the total transport cost savings, defined as the transport costs "without project" less the transport costs "with project." Transport costs to the users consist of two major components: out-of-pocket costs and time costs. A trip by a motor vehicle, for example, involves vehicle operating cost and time costs to the driver and passengers. Time cost is usually valued as a proportion of the trip maker's hourly wage. Thus, if a project saves every user the same amount of travel time, then valued on this (equally weighted) basis, the time cost savings for high-income users will be greater than those for low-income users.

Thus, the project selection will be oriented away from the projects serving the poorer areas, and alternatives (or project components) that serve more lower-income individuals than higher income individuals. As a result, some projects or components for low-income groups which satisfy the criterion of economic efficiency may be eclipsed. This orientation will be reinforced by both public agency capital budget constraints and private firm profitability; the projects serving higher-income groups will be ranked higher. The analysis covers all affected parties users and nonusers in terms of the full social consequences including any externalities.

As an example, consider an urban transport project that supports motorization. The construction of motorized transport infrastructure competes with traditional non-motorized transport and pedestrian facilities for scarce land. With very limited space for transport development, the orientation to the higher productivity of land in motorized facility use displaces land allocated to non-motorized transport facilities. This problem is particularly severe in rapidly growing cities in East Asia. Worse yet, the dynamics of growing use of motorized vehicles eventually changes land use and transport combinations. This is unfavorable to low-income groups who rely mostly on non-motorized vehicles and walking for their trips. Transitions from walking to non-motorized transport to public motorized transport and then to individualized motorized transport do not take place along a continuum; a change from one mode to another for any individual often represents a quantitative jump in terms of travel expenditure. This jump may be a major barrier for the poor to overcome.

Moreover, because of this orientation, transport rights-of-way often displace poor communities. As land prices are typically less expensive in poor communities, the alignments of large-scale road projects 
are often selected to cross these communities. Some projects are accompanied by the redevelopment of poor communities. However, it is less clear whether the benefits of these projects and the redevelopment ultimately benefit the poor. Most poor households rent housing units. Neighborhood quality improvement due to redevelopment may translate to higher rents that displace the poor households and benefit the property owners.

\section{Conclusions}

1. Organizational effectiveness is the degree to which an organization, on the basis of competent management, while avoiding unnecessary exertion, in the more or less complex environment in which it operates, manges to control internal organizational and environmental conditions, in order to provide by means of its own characteristics transformation process, the outputs expected by external constituencies [8].

2. Improvement of transport organizations effectiveness requires a vision - a vision of providing quality services for all transport organizations, but particularly for the most vulnerable social groups.

3. Performance measurement can bring significant benefits, including help to transport organizations to determine effective resource allocation. In the absence of profit, or direct competition, performance measurement is one of the principle ways that the transport organizations determine whether it is providing a quality product or service. However, it is a management tool and is subject to a number of limitations, including concerns about the relevance and robustness of some indicators.

4. There is a variety and range of evaluation techniques, including: cost benefit analysis, economic impact analysis (EIA), modeling, and opinion and client satisfaction surveys.

5. Transport effectiveness refers to the effectiveness of transport agency's organizational systems in achieving its internal and external objectives. The assumption is that effective organizational systems produce consistent standards and behavior in an organization, and ultimately, good country-level results. Poor results can usually be traced in weak organizational systems.

\section{References}

1. Barry Carin and David A. Good. Evaluating efficiency and effectiveness inpublic sector delivery. Prepared as part of the CEPRA project on "Sector and Regional Specifics of Reformation of Budgetary Institutions" for the Kaliningrad Workshop July 24-25, 2004.

2. Cammeron, K. S.; Whetten, D. A. Organizational effectiveness. A comparison of multiple models. New York: Academic Press, 1983.

3. Niskanen, W. A. Bureaucracy and representative government. Chicago: Aldine - Aherton, 1971.

4. Mintzberg, H. The structuring of organizations. Englewood Cliffs: Prentice Hall, 1979.

5. Pfeffer, J.; Salancik, G. R. The external control of organizations: a resource dependence perspective. New York: Harper and Row, 1978.

6. Sceerens, J. Improving school effectiveness. United Nations Educational, Scientific and Cultural Organization. Fundamentals of Education Planning, No 68, 2000, p. 27.

7. Scott, A. Assesing multilateral effectiveness. International Division, DFID February 2004.

8. Kestern, J. H. M. van. Doorlicheter en herontwerpen van organisatiecomplexen. Thesis: University of Groningen, 1996. 